\title{
Vilazodone for the treatment of major depressive disorder: an evidence-based review of its place in therapy
}

This article was published in the following Dove Press journal:

Core Evidence

20 April 2015

Number of times this article has been viewed

\section{David J Hellerstein ${ }^{1,2}$ Joseph Flaxer ${ }^{\prime}$}

'Department of Psychiatry, Columbia University, ${ }^{2} \mathrm{New}$ York State Psychiatric Institute, New York, NY, USA
Correspondence: David J Hellerstein New York State Psychiatric Institute, Unit 5I, 105I Riverside Drive,

New York, NY I0032, USA

Tel +l 6467748069

Fax + I 6467748034

Email hellers@nyspi.columbia.edu

Introduction: It has clearly been demonstrated that depressive disorders constitute a major worldwide public health problem, with massive economic and quality-of-life consequences. Existing pharmacological treatments have limited efficacy, with only about a third of patients achieving remission on any one medication. Delayed onset of action and variable tolerability contribute to this limited efficacy. Vilazodone, introduced in the US in 2011, has been described as the first member of the serotonin partial agonist-reuptake inhibitor (SPARI) class of medications, combining serotonin-reuptake inhibition with 5-HT ${ }_{1 \mathrm{~A}}$ partial agonism. This agent could potentially have benefits for subgroups of depressed patients, including depressed patients with comorbid anxiety and patients with anxiety disorders, and might have fewer sexual side effects than selective serotonin-reuptake inhibitors (SSRIs).

Aims: We reviewed existing clinical trials that assess the benefits of vilazodone for treatment of major depression.

Evidence review: In clinical trials, including two Phase III studies and two Phase IV studies, vilazodone has been shown to have efficacy greater than placebo on the Montgomery-Åsberg Depression Rating Scale, comparable efficacy to citalopram, and continued benefit after 52 weeks of treatment. The safety profile for vilazodone is comparable to other SSRI medications, and tolerability also appears generally comparable to other SSRI medications.

Place in therapy: Vilazodone, which has been described as the first-of-class SPARI medication, may potentially have benefits for subgroups of patients, particularly those depressed individuals with coexisting anxiety symptoms or anxiety disorders. However, convincing evidence for these benefits has as yet not been published.

Keywords: vilazodone, antidepressant, pharmacology, major depression

\section{Clinical impact summary for vilazodone in major depression}

\begin{tabular}{|c|c|c|}
\hline Outcome measure & Evidence & Implications \\
\hline \multicolumn{3}{|l|}{ Patient-oriented evidence } \\
\hline $\begin{array}{l}\text { Reduction of depressive } \\
\text { symptoms }\end{array}$ & Clear & $\begin{array}{l}\text { Vilazodone more effective than placebo As effective } \\
\text { as citalopram }\end{array}$ \\
\hline Improvement of anxiety & Suggestive & $\begin{array}{l}\text { Vilazodone may have additional benefit for depressed } \\
\text { patients with high levels of anxiety }\end{array}$ \\
\hline \multicolumn{3}{|l|}{ Disease-oriented evidence } \\
\hline $\begin{array}{l}\text { Symptom relief in terms } \\
\text { of MADRS reduction }\end{array}$ & Clear & Vilazodone more effective than placebo on MADRS \\
\hline Response to treatment & Clear & Vilazodone more effective than placebo \\
\hline Remission after treatment & Clear & Vilazodone more effective than placebo \\
\hline \multicolumn{3}{|l|}{ Economic evidence } \\
\hline Cost-effectiveness & $\begin{array}{l}\text { No } \\
\text { evidence }\end{array}$ & $\begin{array}{l}\text { So far, there is no information regarding the relative } \\
\text { cost-effectiveness of vilazodone compared to other } \\
\text { marketed antidepressants in the US }\end{array}$ \\
\hline
\end{tabular}




\section{Scope, aims, and objectives Methods}

The medical literature was reviewed for appropriate articles related to vilazodone on PubMed (http://www.ncbi.nlm.nih. gov) using the search term "vilazodone" and EMD 68843, its investigational name. The search was performed on Medline in June 2014 and updated on October 24, 2014 and January 2,2015 . The initial search using the term "vilazodone" provided 76 results, of which 48 were human studies, including six clinical trials, 25 reviews, and one case report. Posters presented at relevant medical conferences were included if posted online and accessible through a Google search $(n=4)$. The US clinical trials registry ClinicalTrials.gov was accessed to determine ongoing $(n=13)$ and completed $(n=11)$ human subjects studies involving vilazodone. The six reports of clinical trials (five published articles, one abstract), including four placebo-controlled randomized clinical trials (RCTs), one switch study, and one 52-week continuation study, are cited in this review (Table 1). In addition, five secondary data analyses derived from these vilazodone trials are included in this review. So far, no pharmacoeconomic studies of vilazodone have been published. The results of included clinical trials and secondary data analyses are reviewed with a focus on clinical efficacy, safety, and tolerability of vilazodone in the treatment of major depression.

\section{Disease overview}

Major depressive disorder (MDD) is a widespread, debilitating illness. ${ }^{1}$ According to the World Health Organization,

Table I Evidence base included in this review

\begin{tabular}{lll}
\hline Category & \multicolumn{2}{l}{ Number of records } \\
\cline { 2 - 3 } & Full papers & Abstracts \\
\hline Initial search & 82 & 5 \\
Records excluded & 12 & $\mathrm{I}$ \\
Records included & 70 & 4 \\
Total records included & 6 & 4 \\
Level I clinical evidence & $\mathrm{I}$ & $\mathrm{I}$ \\
(systematic review, meta-analysis) & & \\
Level 2 clinical evidence (RCT) & 4 & 0 \\
Level $\geq 3$ clinical evidence & & \\
Trials other than RCTs & $\mathrm{I}$ & $\mathrm{I}$ \\
Secondary analysis of RCT data & 4 & $\mathrm{I}$ \\
Case reports & $\mathrm{I}$ & 0 \\
Other outcome than depression (RCTs) & $\mathrm{I}$ & $\mathrm{I}$ \\
Economic evidence & 0 & 0
\end{tabular}

Note: For definitions of levels of evidence, see Core Evidence website (http:// dovepress.com/core-evidence-journal).

Abbreviation: RCT, randomized clinical trial. unipolar depressive disorders rank third among leading causes of global disease burden. ${ }^{1,2}$ Depression is often recurrent, and leads to medical and psychiatric morbidity, functional disability, and steep health care costs. ${ }^{3,4}$ While there are a number of different treatments options for physicians, many patients do not reach an adequate response, even after multiple treatment regimens. Although two-thirds improve with initial treatment, only a third of patients remit. ${ }^{5}$ Also, those who do remit often take weeks to do so. However, it has also been shown that while treatment effects are modest overall regardless of initial therapy, some nonresponders to one treatment may still be responsive to an alternative medication. While long-term treatment decreases the odds of relapse by as much as $70 \%,{ }^{6}$ only $25 \%-50 \%$ of patients comply with their prescribed regimen. ${ }^{7,10}$ Lack of efficacy, in addition to tolerability issues like sexual dysfunction, is often behind cases of noncompliance.

Vilazodone, a serotonin 1A (5- $\left.\mathrm{HT}_{1 \mathrm{~A}}\right)$-receptor partial agonist and serotonin-reuptake inhibitor, ${ }^{8}$ is a new molecule that has been shown in four randomized control trials (ClinicalTrials.gov NCT00285376, ${ }^{11}$ NCT00683592, ${ }^{12}$ NCT01473394, ${ }^{13}$ and NCT01473381) $)^{14}$ to be efficacious in the treatment of depression. ${ }^{15}$ This dual modulation of serotonin has been shown in nonclinical studies to increase serotonin levels more than selective serotonin-reuptake inhibitors (SSRIs). ${ }^{8}$ Based on animal studies, it has been surmised that the especially high selectivity of vilazodone for the $5-\mathrm{HT}_{1 \mathrm{~A}}$ receptor could potentially lead to greater tolerability, due to less disruption of other neurotransmitter systems. ${ }^{16}$ Specifically, it has been suggested that vilazodone may be associated with less sexual dysfunction than conventional SSRIs. ${ }^{11,17}$ In addition, vilazodone's unique mechanism could potentially make it more effective than conventional SSRIs in the treatment of anxious depression. ${ }^{18,19}$

\section{Current therapy options}

Numerous antidepressant medications have been available for the treatment of depression for over half a century, including tricyclic antidepressants and the monoamine oxidase inhibitors, introduced in the 1950s, the SSRIs, introduced in the 1980s and 1990s, the serotonin norepinephrine-reuptake inhibitors (SNRIs), which were introduced beginning with venlafaxine in 1994, and atypical agents, including bupropion and trazodone, which have also been available for decades. In recent years, it has widely been reported that the pharmaceutical industry has a "dry pipeline", ${ }^{20}$ and the question has been raised: "Is there anything really novel on the 
antidepressant horizon?"21 Murrough and Charney ${ }^{21}$ observed that monoaminergic agents still dominate the antidepressant development pipeline, and that drugs now in the pipeline that do have other potential mechanisms of action, such as via the glutamatergic pathway, ${ }^{22}$ are not yet ready for clinical use.

As such, new antidepressant agents introduced over the past decade fall into two classes. First are compounds with similar mechanisms of action to existing medications. For instance, there is the SNRI levomilnacipran, ${ }^{23}$ which is similar to other SNRIs, though reportedly with relatively more balanced norepinephrine and serotonin reuptake than other SNRIs. For levomilnacipran, it is not clear whether more balanced serotonin reuptake-inhibitory and norepinephrine reuptake-inhibitory activity leads to better tolerability or increased efficacy. Second, other new drugs introduced over the past decade combine SSRI activity with additional receptor activity. The latter class includes vortioxetine (US brand name Brintellix), ${ }^{24-26}$ which in addition to serotoninreuptake inhibition also is a $5-\mathrm{HT}_{3}$ receptor antagonist and a $5-\mathrm{HT}_{1 \mathrm{~A}}$ agonist. Similarly, vilazodone (US brand name Viibryd $)^{8,12,27-34}$ combines selective SSRI activity with 5-HT partial agonist activity. For both vortioxetine and vilazodone, it is still unclear whether their additional receptor activity leads to better clinical efficacy. There are reports that vortioxetine may have positive neurocognitive effects, ${ }^{25,26}$ and suggestions, discussed later, that vilazodone ${ }^{9,19}$ might have particular efficacy for anxious depression and may have a better tolerability profile. However, to date there is no convincing evidence that any of the new medications represents a significant advance over previous pharmacological options.

\section{Unmet needs}

Numerous reviews (eg, Hansen et al) ${ }^{35}$ have demonstrated that the efficacy of existing antidepressant medications is limited, without dramatically increased benefit for the second-generation medications, and some authors have questioned whether antidepressants have any efficacy at all. ${ }^{36,37}$ Response rates in major depression are generally in the 50\%-70\% range, and remission averages 30\% (for instance, 28\% remission to citalopram as rated by Hamilton Depression Rating Scale [HAMD] and 33\% rated by Quick Inventory of Depressive Symptomatology - self-related [QIDS-SR] in the STAR*D study). ${ }^{10,38}$ Clearly, many patients have only partial response to antidepressant medication or are nonresponders. The reasons for this limited efficacy are unclear, and clinicians still lack the ability to predict treatment response in a meaningful way. Furthermore, existing oral antidepressant medications have a delayed onset of action, generally requiring several weeks of treatment before initiation of medication response (ketamine is reported to have more rapid onset of action, but currently requires intravenous administration). ${ }^{39}$ There is also a significant need for effective medications for patients with bipolar depression, as demonstrated in the STEP-BD study, in which antidepressant medications added to mood stabilizers led to no additional antidepressant effect compared to mood stabilizer alone. $^{40}$

Evidence in published studies to date for newly introduced medications, such as vilazodone or vortioxetine, although limited, does not yet provide convincing support for significantly improved efficacy compared to existing SSRI/SNRI medications. However, there are particular needs for effective treatments for subgroups of depressed patients for which these new agents might have significant benefit. Patients with depression and comorbid cognitive impairment might potentially respond to vortioxetine, for example. ${ }^{25,26}$ Similarly, patients with anxious depression (in the Diagnostic and Statistical Manual of Mental Disorders, Fifth Edition [DSM-5], this has been delineated with an added specifier - "with anxious distress" - which can be added to unipolar or bipolar depression, and includes feelings of being keyed up or tense, unusual restlessness, difficulty concentrating because of worry, etc) might potentially respond better to vilazodone, which as noted by Stahl ${ }^{9}$ combines the pharmacological properties of an SSRI and the anxiolytic buspirone. Furthermore, vilazodone might be beneficial for individuals with other disorders, such as anxiety disorders (generalized anxiety disorder, panic disorder, social anxiety disorder) and for posttraumatic stress disorder. ${ }^{41}$

Furthermore, there is a significant need for drugs with greater tolerability, such as less weight gain and less sexual dysfunction, in order to enhance adherence to long-term medication treatment regimens.

\section{Clinical evidence for vilazodone in the treatment of major depression Clinical efficacy assessment}

As noted earlier, vilazodone, approved by the US Food and Drug Administration (FDA) in 2011 and marketed in the US from July of that year, has SSRI activity and is also a partial agonist of the $5-\mathrm{HT}_{1 \mathrm{~A}}$ receptor. It has been characterized as a serotonin partial agonist-reuptake inhibitor (SPARI). ${ }^{9}$ Stahl outlines three potential benefits of SPARI medications: 1) faster onset of action, 2) greater efficacy, and 3) better 
tolerability, in particular lower sexual side effects. ${ }^{9}$ The evidence to support such possible benefits is as follows.

\section{Onset of action}

In animal models, adding this novel mechanism of 5-HT ${ }_{1 \mathrm{~A}}$ partial agonism to SSRIs has been shown to cause a more rapid and augmented elevation of brain 5-HT versus an SSRI alone. ${ }^{8,42}$ As Stahl puts it, ${ }^{9} 5-\mathrm{HT}_{1 \mathrm{~A}}$ partial agonists are "a type of 'artificial serotonin' selective especially for presynaptic somatodendritic 5-HT $\mathrm{HA}_{1 \mathrm{~A}}$ autoreceptors, and that $5-\mathrm{HT}_{1 \mathrm{~A}}$ partial agonist action occurs immediately after the drug is taken".9,42 Stahl explains that when vilazodone is ingested, about $50 \%$ of serotonin transporters (SERTs) and 50\% of serotonin $5-\mathrm{HT}_{1 \mathrm{~A}}$ receptors are immediately occupied. The inhibition of the SERT at first causes serotonin to increase in the somatodendritic area of the serotonin neuron. As a result, the somatodendritic 5-HT $\mathrm{HA}_{1 \mathrm{~A}}$ autoreceptors desensitize and downregulate. Consequently, there is no longer inhibition of impulse flow in the serotonin neuron. As neuronal impulse flow is activated, there is a release of serotonin in the axon terminal. As such, immediate $5-\mathrm{HT}_{1 \mathrm{~A}}$ partial agonist actions are thought to be additive or synergistic with SERT inhibition, since this leads to faster and more robust actions at $5-\mathrm{HT}_{1 \mathrm{~A}}$ somatodendritic autoreceptors than with SERT inhibition alone. This would cause faster and stronger elevation of synaptic 5-HT than would SSRIs alone. However, if clinical studies do not support this theoretical notion, it may not be useful in practice. ${ }^{11,43}$ In humans, the quick increase in serotonin is often not well tolerated, especially due to gastrointestinal side effects. If the rate of dose titration must reduced in order to minimize such side effects, this could potentially neutralize the benefit of rapid antidepressant onset. ${ }^{9}$

\section{Greater efficacy}

$\mathrm{Stahl}^{9}$ has suggested that vilazodone (and other SPARIs), by combining the properties of buspirone or atypical antipsychotics that have been used for augmentation of SSRIs and SNRI actions "could potentially have greater antidepressant efficacy than selective SERT inhibition". However, like a faster onset of action, this property has not yet been shown in head-to-head trials of vilazodone versus an SSRI either. Of note, the receptor activity of vilazodone may be complex, as shown by Hughes et al. ${ }^{8}$ In rodent experiments, vilazodone and the $5-\mathrm{HT}_{1 \mathrm{~A}}$ agonist 8-OH-DPAT do not behave identically, and neither do vilazodone and the clinically marketed 5-HT agonist buspirone. Hughes et $\mathrm{al}^{8}$ argue that vilazodone has less $5-\mathrm{HT}_{1 \mathrm{~A}}$ partial agonist activity than buspirone, and as a result is more effective at increasing serotonin levels in the synaptic cleft. He says that the level of intrinsic activity of vilazodone ( $\sim 61 \%$ versus $100 \%$ for a full agonist) is significantly less than buspirone $(\sim 19 \%)$. This level of intrinsic activity is comparable to what was shown by Page et $\mathrm{al}^{44}$ in a human clonal system, and suggests that vilazodone has high efficacy as a partial agonist at 5- $\mathrm{HT}_{1 \mathrm{~A}}$ receptors. However, Hughes et $\mathrm{al}^{8}$ state that vilazodone's "profile was similar to that seen with a $5-\mathrm{HT}_{1 \mathrm{~A}}$ receptor antagonist plus an SSRI but in contrast to 8-OH-DPAT either alone or in combination with paroxetine".

\section{Sexual dysfunction}

As briefly mentioned earlier, a notable difference between buspirone plus an SSRI/SNRI compared to vilazodone is that when buspirone is administered with an SSRI, the dosing of buspirone and the dosing of the SSRI leads to an occupancy of $10 \%-20 \%$ of $5-\mathrm{HT}_{1 \mathrm{~A}}$ receptors and an inhibition of $80 \%$ of SERT receptors. ${ }^{9}$ In contrast, neuroimaging studies in humans indicate that vilazodone is dosed in a way that leads to $50 \%$ occupancy of both the 5-HT ${ }_{1 \mathrm{~A}}$ and SERT receptors. ${ }^{45}$ It is currently unknown whether this difference could lead to any clinically significant differences in vilazodone monotherapy versus the augmentation of SSRIs/SNRIs with buspirone or atypical antipsychotics. ${ }^{9}$ Stahl speculated that this difference in receptor occupancy could account for the conjectured lower incidence of sexual dysfunction with vilazodone. ${ }^{9}$ In sum, the SPARI mechanism could potentially cause less sexual dysfunction than SSRIs, as a result of less serotoninreuptake inhibition.

\section{Clinical efficacy of vilazodone in Phase II, III, and IV trials}

Emerging data from vilazodone clinical trials ${ }^{11-14,46,47}$ and secondary data analyses ${ }^{19,28,48-50}$ have now begun to address possible benefits of quicker onset, greater efficacy, and better tolerability, as described in the following sections.

\section{Symptomatic relief and medication response}

Five trials (FDA-approval package) using doses from 5 to $100 \mathrm{mg} /$ day were carried out as part of the Phase II program for vilazodone. According to Laughren et $\mathrm{al}^{34}$ however, none of these trials demonstrated a statistically significant treatment effect of vilazodone on its primary endpoint the HAMD. However, as Laughren et $\mathrm{al}^{34}$ describe, on a secondary end point - the Montgomery-Åsberg Depression Rating Scale (MADRS) - two fixed-dose trials showed dose responses for the difference between vilazodone and placebo, suggesting a treatment effect for the $20 \mathrm{mg}$ /day vilazodone 
groups. Overall, for these Phase II trials, depression symptoms tended to decrease as daily doses increased to $20 \mathrm{mg}$. However, doses above $20 \mathrm{mg}$ /day did not appear to lead to additional decrease in MADRS scores, ${ }^{34}$ though the recommended therapeutic dose is $40 \mathrm{mg} /$ day.

In a 2009 Phase III RCT (NCT00285376), Rickels et $\mathrm{al}^{17}$ found that vilazodone at a dose of $40 \mathrm{mg} /$ day led to a statistically significant decrease in depressive symptoms in an 8-week treatment of MDD in adults. Statistically significant reductions in MADRS HAMD-17, Clinical Global Impression - Improvement (CGI-I), and CGI - Severity (CGI-S) scale scores were observed with vilazodone versus placebo, including significant differences on the MADRS and HAMD-17 at week 1 .

In Khan et al's' 2011 Phase III RCT (NCT00683592), during 8 weeks of treatment with vilazodone at $40 \mathrm{mg} /$ day, improvement in symptoms of depression was also statistically significant and observed on multiple measures, including the MADRS, HAMD-21, and HAMD-17. Also, vilazodone use was associated with improvements in measures of overall illness severity (CGI-S and CGI-I). However, remission rates at the end point were not statistically different for vilazodone compared to placebo.

Citrome $^{28}$ pooled these two studies, defining response as a reduction from baseline to an end point of at least $50 \%$ in MADRS total score, and remission as achieving a MADRS total score less than 10 at the end point. He determined that the number needed to treat (NNT) for vilazodone versus placebo for response was eight $(95 \%$ confidence interval 6-16) and for remission was 14 (95\% confidence interval $8-55)$.

Two additional randomized placebo-controlled studies have been recently published. In a 10-week Phase IV RCT (NCT01473381) comparing a $20 \mathrm{mg} /$ day dose $(\mathrm{n}=288)$ and a $40 \mathrm{mg} /$ day dose vilazodone $(\mathrm{n}=287)$ and citalopram $40 \mathrm{mg} /$ day $(\mathrm{n}=282)$ versus placebo $(\mathrm{n}=281)$, Mathews et $\mathrm{al}^{14}$ found that each of the active medication-treated groups were superior to placebo. MADRS score improvement was significantly greater for vilazodone $20 \mathrm{mg} /$ day (least squares mean difference [LSMD] -2.57 ; adjusted $P=0.0073$ ), vilazodone 40 $\mathrm{mg}$ /day (LSMD -2.82 , adjusted $P=0.0034$ ), and citalopram (LSMD -2.74, adjusted $P=0.0020$ ) compared with placebo. Mathews et $\mathrm{al}^{14}$ also showed a similar finding for symptom severity, as rated by the CGI-S scale, which were significantly more improved with vilazodone $20 \mathrm{mg}$ /day (LSMD -0.35 , adjusted $P=0.0073$ ), vilazodone $40 \mathrm{mg} /$ day (LSMD -0.33 , adjusted $P=0.0097$ ), and citalopram $40 \mathrm{mg} /$ day (LSMD $-0.35, P=0.0025)$ than for placebo.
This is the only published study to date to include an SSRI comparator (citalopram), vilazodone, and placebo. However, it was not powered to make direct comparisons between the active agents, only to compare them to placebo. As a result, statistical analyses in Mathews et $\mathrm{al}^{14}$ did not compare the efficacy of different vilazodone doses or compare vilazodone to citalopram. Nevertheless, the score changes in the primary outcome (MADRS) and secondary outcomes (CGI-S, sustained MADRS response) appeared largely similar between vilazodone and citalopram, without even a hint of faster onset or greater efficacy for vilazodone in this study sample.

Croft et al ${ }^{13}$ reported on an 8-week Phase IV randomized double-blind placebo-controlled study of MDD treating 253 patients with vilazodone $40 \mathrm{mg} /$ day and 252 with placebo (NCT01473394). The primary outcome was MADRS total score, with secondary outcomes of CGI-S and MADRS sustained-response scores (total score $\leq 12$ ) for the last two consecutive double-blind visits. The study found that there were significant differences on total MADRS score for vilazodone versus placebo. MADRS score improvement was significantly greater for vilazodone $40 \mathrm{mg} /$ day than placebo (LSMD -5.12 , adjusted $P<0.00001$ ). Similarly, CGI-S total score showed significantly more improvement for vilazodone-treated subjects than placebo (LSMD -0.622 , $P<0.00001)$.

In addition, Patkar et $\mathrm{al}^{46}$ reported in a poster at the American Society of Clinical Psychopharmacology on an 8-week study in which 71 patients were switched from ineffective SSRI or SNRI medications to vilazodone 10, 20, or $40 \mathrm{mg} /$ day. In this study, there was no washout period: instead, patients were abruptly switched from SSRI/SNRI medication to vilazodone. The primary outcome of that study was MADRS total score, and the secondary outcome was a measure of Discontinuation-Emergent Signs and Symptoms (DESS), a scale used to evaluate SSRI-discontinuation symptoms. ${ }^{51}$ Of 71 subjects randomized, 60 completed the study. Overall, Patkar et $\mathrm{al}^{46}$ reported a significant reduction in mean \pm standard error of mean in MADRS score from baseline $(26.08 \pm 1.1)$ to week $8(9.86 \pm 1.2)$ in the three groups combined $(P<0.001)$, and that there were no significant differences between the three vilazodone dose-initiation groups in mean changes in MADRS $(P=0.95)$, CGI-S $(P=0.83)$, CGI-I $(P=0.51)$, or Hamilton Anxiety Rating Scale (HAMA) scores $(P=0.61)$. DESS scores appeared to have decreased from baseline (5.9 \pm 9.9$)$ to week $8(2.2 \pm 5.5, P<0.01)$, with no significant differences between the three starting doses of vilazodone. Overall, there appeared to be a good level of 
tolerability for a sudden switch from an SSRI or SNRI to vilazodone.

\section{Onset of action}

With regard to the hypothesized ${ }^{9}$ earlier onset of treatment effect, Rickels et al found statistically significant reductions in MADRS and HAMD-17 with vilazodone versus placebo beginning at week $1 .{ }^{11}$ Perez et al ${ }^{52}$ noted "this rapid time course of efficacy remains to be validated." Some further data has recently emerged. In Croft et al, ${ }^{13}$ statistically significant improvement versus placebo also occurred early in the trial, starting at week 2 and continuing for the duration of the 10 -week study. The same finding was seen in the Mathews et $\mathrm{al}^{14}$ study cited earlier: statistically significant improvement was observed in MADRS and CGI-S scores starting at week 2 and continuing through the trial. This separation from placebo was observed for both $20 \mathrm{mg} /$ day and $40 \mathrm{mg} /$ day doses of vilazodone, as well as for citalopram $40 \mathrm{mg} /$ day.

To give these findings some context, as Stewart et $\mathrm{al}^{6}$ stated, "The idea that antidepressant medications have delayed onset of efficacy has been challenged by re-analyses of data suggesting active drugs may separate from placebo as early as 1 week. This early separation suggests that at least in some patients, the medications have actions not previously considered. However, even the strongest proponents of the early onset of antidepressant action do not suggest that drug-induced early remissions are likely". ${ }^{53}$ Data for vilazodone $^{50}$ demonstrate low rates of remission at week 1 ( $0.8 \%$ for vilazodone, $0 \%$ for placebo) and week $2(2.8 \%$ for vilazodone, $2.8 \%$ for placebo), with statistically significant differences in remission occurring only by week $6(29.9 \%$ for vilazodone, $15.5 \%$ for placebo). Therefore, to date there is little to support hypothesized claims for greater earlier meaningful relief of symptoms for vilazodone in comparison to other antidepressants.

\section{Achieving remission}

What about the hypothesized greater efficacy ${ }^{9}$ of vilazodone as an SPARI medication? In a review of the initial two pivotal Phase III trials for vilazodone - Rickels et $\mathrm{al}^{11}$ and Khan et $\mathrm{al}^{12}-\mathrm{Citrome}^{28}$ noted that pooled response rates were $29.2 \%$ for placebo and $42.4 \%$ for vilazodone $40 \mathrm{mg}$ / day remission, and remission rates were $18.1 \%$ for placebo and $25.4 \%$ for vilazodone, where response was defined as a reduction from baseline to end point of at least $50 \%$ in MADRS total score and remission defined as achieving a MADRS total score $<10$ at end point. This is not substantially different from STAR *D, which found remission rates of $28 \%$ using the HAMD scale and 33\% using the QIDS-SR scale for citalopram ${ }^{10}$ (the $\mathrm{STAR} * \mathrm{D}$ citalopram response rate was $47 \%$ for QIDS-SR).

More recently (2014), Citrome et $\mathrm{al}^{50,54}$ reported on the efficacy of vilazodone in achieving remission from MDD in a post hoc analysis of a Phase IV study comparing vilazodone $40 \mathrm{mg} /$ day versus placebo. ${ }^{50}$ Croft et al ${ }^{13}$ (NCT01473394) enrolled adults aged 18-70 years with initial diagnosis of $D S M-I V$-TR MDD and MADRS $\geq 26$. Post hoc analyses were done for patients achieving response (MADRS $<10$ ), remission (MADRS <5), anxiety-symptom remission (HAMA $\leq 7$ ), and combined depression/anxiety-symptom remission $($ MADRS $\leq 10+$ HAMA $\leq 7)$. At week 8 , a significantly greater percentage of vilazodone patients compared with placebo patients achieved MADRS remission (NNT 9, 34\% versus $22 \%$, odds ratio [OR] $1.82 ; P=0.003$ ) and complete remission (NNT 10, 18\% versus $8 \%$, OR $2.42 ; P=0.002$ ). A greater proportion of vilazodone patients relative to placebo patients met criteria for HAMA remission (NNT 8, 49\% versus $35 \%$, OR $1.82 ; P=0.002)$ and combined MADRS/ HAMA remission (NNT 9, 32\% versus 20\%, OR 1.84; $P=0.004)$. In addition, patients with higher baseline depressive severity had a greater likelihood of achieving remission on all remission outcomes.

Unfortunately, Mathews et al, ${ }^{14}$ the only study including an SSRI as well as vilazodone, did not report remission rates. However, they did assess for MADRS "sustained response" (defined as MADRS total score $\leq 12$ for at least the last two consecutive double-blind visits). The various active medication-treatment groups had numerical superiority to placebo: sustained response was seen in the $29.9 \%$ of vilazodone $20 \mathrm{mg}$ /day subjects, $33.5 \%$ of vilazodone $40 \mathrm{mg} /$ day subjects, and $31.1 \%$ of citalopram-treated subjects versus $26.3 \%$ of placebo-treated subjects. However, these differences were not statistically significant. Furthermore, the remission rates for vilazodone and citalopram were essentially identical. Patkar et al's medication-switching study abstract ${ }^{46}$ did not report response or remission rates.

\section{Specific subgroups of depressed patients}

\section{Anxiety}

As Rickels et al ${ }^{17}$ mention, past clinical studies evaluating the $5-\mathrm{HT}_{1 \mathrm{~A}}$-receptor function have concluded that the $5-\mathrm{HT}_{1 \mathrm{~A}}$ receptor is impaired in patients with depression and is involved in the pathogenesis of depression and anxiety. ${ }^{16}$ Recent results of a large clinical trial ${ }^{55}$ with the $5-\mathrm{HT}_{1 \mathrm{~A}}$ agonist gepirone showed significant antidepressant efficacy. Fava et $\mathrm{al}^{56}$ also showed that patients with anxious depression 
were less responsive to antidepressant therapy than those with nonanxious depression. Furthermore, 5-HT ${ }_{1 \mathrm{~A}}$ agonists have significant effects in patients with symptoms of anxiety and depression. ${ }^{57,58}$

What effect does vilazodone have on anxiety symptoms in depressed patients? In the Rickels et $\mathrm{al}^{11}$ and Khan et $\mathrm{al}^{12}$ vilazodone studies, statistically significant improvements were demonstrated on HAMA ${ }^{59}$ and HAMD-17 scores. ${ }^{60}$ In a post hoc analysis, Thase et $\mathrm{al}^{19}$ pooled the data of these two studies to learn more about the potential of vilazodone in treating MDD with "prominent" symptoms of anxiety. Thase et al's ${ }^{19}$ analysis divided patients into anxious and nonanxious subgroups, and used least squares mean changes in HAMD-17 and MADRS total scores to evaluate changes in depressive symptoms. Additionally, changes in anxiety symptoms within the anxious subgroup were analyzed using the HAMA total and subscale (Psychic anxiety, Somatic anxiety) scores, HAMD-17 Anxiety/Somatization subscale and item (Psychic anxiety, Somatic anxiety) scores, and the MADRS Inner tension item score.

Thase et $\mathrm{al}^{19}$ found that after 8 weeks of treatment, least squares mean differences between vilazodone and placebo for changes in HAMA total and HAMD-17 Anxiety/ Somatization subscale scores were -1.82 (95\% confidence interval -2.81 to $-0.83, P<0.001)$ and -0.75 (95\% confidence interval -1.17 to $-0.32, P<0.001$ ), respectively. With the exception of the HAMA Somatic Anxiety subscale, statistically significant improvements with vilazodone were also found on all other anxiety-related measures. Of the handful of interesting results, Thase et $\mathrm{al}^{19}$ looked at changes in the overall depression measures in the nonanxious subgroup and the anxious subgroup to analyze potential differences in treatment effects. Findings suggested larger mean improvements with vilazodone versus placebo in the anxious subgroup relative to the nonanxious subgroup (however, only $18 \%$ of pooled vilazodone subjects had nonanxious depression at baseline). This finding was "somewhat unexpected", as similar analyses with other antidepressants often have not found a difference or have found lower efficacy among patients with anxious depression. ${ }^{56,61}$ The authors concluded that these results might point to vilazodone having benefits in treating depression with "prominent" anxiety symptoms, and that due to the statistical limitations, further research is warranted. Overall, Thase et a ${ }^{19}$ concluded that "vilazodone may be effective in treating patients with major depressive disorder who exhibit somatic and/or psychic symptoms of anxiety".
In two recently reported placebo-controlled vilazodone RCTs, HAMA scores have been reported. In Mathews et al, ${ }^{14}$ there was no significant difference for vilazodone $20 \mathrm{mg}$ /day or vilazodone $40 \mathrm{mg}$ /day on HAMA scores compared to placebo. Change from baseline at week 10 ranged from -7.4 $(0.4)$ to $-7.5(0.4)$ for the active treatments compared to placebo -6.7 (0.4). Perhaps counterintuitively, citalopram $40 \mathrm{mg}$ /day treatment -7.9 (0.4) was associated with significant change in HAMA scores $(P=0.0138)$.

In contrast, in Croft et al, ${ }^{13}$ HAMA scores did improve significantly with vilazodone treatment. HAMA scores decreased from baseline to week $8(-7.5$ [0.4]) for vilazodone $40 \mathrm{mg} /$ day compared to $-5.0(0.4)$ for placebo $(\mathrm{LSMD}=-2.118, P<0.00001)$.

\section{Ongoing studies}

A review of studies on ClinicalTrials.gov (performed October 21,2014 ) showed a total of 24 studies involving vilazodone. Of these, eleven were listed as completed (three with results) and 13 were ongoing. A number of these were mandated by the FDA at the time of vilazodone's approval, ${ }^{34}$ including a maintenance study, a study of $20 \mathrm{mg} /$ day dosing, a pediatric program, a cytochrome P450 (CYP)-3A4 inducer study, a study of severe hepatic impairment, and a P-glycoprotein interaction study. The three studies with results included: Safety and Efficacy of Vilazodone in Major Depressive Disorder; Safety, Efficacy, and Tolerability of Vilazodone in Major Depressive Disorder; and Randomized, Double-Blind, Placebo Controlled Study of Vilazodone's Efficacy, Safety, and Biomarkers of Response in Major Depressive Disorder (MDD). These studies presumably were completed for FDA registration of vilazodone.

Studies listed on ClinicalTrials.gov as completed but without listed results (as of October 2014) and ongoing studies included a variety of Phase IV studies, including vilazodone for the treatment of social anxiety disorder, generalized anxiety disorder, separation-anxiety disorder, corticosteroid-induced memory impairment, posttraumatic stress disorder, menopausal hot flashes, marijuana dependence, and geriatric depression, and to investigate effects on decision making in MDD. Furthermore, there was a listing for a comparison study between vilazodone and citalopram in the treatment of MDD, and a comparison between two doses of vilazodone (20 and $40 \mathrm{mg}$ ) versus paroxetine $20 \mathrm{mg}$ versus placebo on sexual functioning of healthy adults. There was a 1-year long-term tolerability study. There were also some biological studies: one looking at genetic markers associated with response in MDD, and another examining 
the effects of glutamate on the anterior cingulate cortex in anxious unipolar depressives. In addition, Rickels et a ${ }^{17}$ state that a "key feature of the vilazodone clinical development program is the identification and development of biomarkers that predict response to therapy", which presumably includes the listed study Effectiveness Study of Vilazodone to Treat Depression and to Discover Genetic Markers Associated with Response, which enrolled 400 subjects and compared vilazodone $40 \mathrm{mg}$ /day to placebo for MDD over an 8-week treatment period.

In summary, a number of these Phase IV studies are investigating the efficacy of vilazodone for treatment of a range of anxiety disorders. This is a logical choice, given the $5-\mathrm{HT}_{1 \mathrm{~A}}$ agonism and SRI activity of vilazodone, which in a sense combine the effects of the anxiolytic buspirone with SRI antidepressant effects. It remains to be seen whether this pharmacological activity leads to better clinical outcome in those disorders. Similarly, the potential efficacy of vilazodone in other areas (such as marijuana abuse) and the tolerability of vilazodone (eg, in terms of sexual side effects, as well as over long-term administration), and its benefits and tolerability for specific subpopulations of patients (such as the elderly) remain to be established. Genetic markers predicting medication response, if found, would potentially be clinically useful.

\section{Safety and tolerability}

Does vilazodone have a higher degree of tolerability and fewer side effects than other antidepressant agents, the third hypothesized benefit of SPARI medications? (The specific issue of sexual side effects is addressed in the "Sexual dysfunction" section). In general, vilazodone does have a relatively high level of safety and tolerability in adults. The rate of medication discontinuation due to side effects, as noted by Citrome's ${ }^{28}$ review of two registration trials, ${ }^{11,12}$ is relatively low: $7.0 \%$ for vilazodone versus $3.1 \%$ for placebo. The only published $\mathrm{RCT}^{14}$ that included vilazodone and an SSRI showed generally comparable rates of discontinuation for vilazodone and citalopram: $6.4 \%$ for citalopram and $6.9 \%$ and $8.7 \%$ for vilazodone 20 and $40 \mathrm{mg}$, respectively, versus $2.5 \%$ for placebo (no statistical analysis was presented).

\section{Patient group/population}

\section{Adults}

Rickels et al $^{11}$ ran an 8-week study of 205 patients treated with vilazodone and 205 treated with placebo, in which patients randomly assigned to vilazodone were administered doses that were titrated to $40 \mathrm{mg}$ once a day. However, patients who experienced side effects at $20 \mathrm{mg}$ could remain at that dose, and patients who experienced intolerable side effects at $40 \mathrm{mg}$ were switched to $20 \mathrm{mg}$ /day for the rest of the study. It was found that the most common treatment-emergent adverse events (TEAEs) in the vilazodone group were diarrhea (23.9\%), nausea (18.5\%), and headache (13.2\%). In comparison, the placebo group had lower incidences of diarrhea (7.3\%) and nausea (4.4\%), but a very similar incidence of headache (14.2\%). Most AEs were of mild or moderate intensity. Overall, discontinuation due to AEs in the vilazodone group was seen in 19 patients $(9.3 \%)$ compared with ten (4.9\%) in the placebo group. In the vilazodone group, there were AEs in 164 patients $(80.0 \%)$, while in the placebo group there were AEs in $130(63.7 \%)$ patients. It was also found that the median duration of nausea was 4 days and diarrhea was 5 days in the vilazodone group compared with 4.5 and 4 days, respectively, in the placebo group. Most AEs in the vilazodone group were reported in week 1 of treatment. Eighteen patients $(8.8 \%)$ in the vilazodone group and eleven patients (5.4\%) in the placebo group had a "severe" AE. The majority of AEs were reportedly of mild or moderate intensity.

In an 8-week study of 240 patients treated with vilazodone titrated to $40 \mathrm{mg}$ /day and 241 treated with placebo, Khan et al $^{12}$ found that the most common AEs were diarrhea (31\%), nausea (26\%), and headache (13\%). As in the Rickels et $\mathrm{al}^{11}$ study, the placebo group had lower rates of diarrhea $(11 \%)$ and nausea (6\%), and similar rates of headache (10\%). Median time to initial onset of diarrhea was 2 days for vilazodone patients and 8 days for placebo patients, and median time to initial onset of nausea was 4 days for vilazodone patients and 2 days for placebo patients. Median duration of the initial occurrence of diarrhea was 8 days for vilazodone patients and 5 days for placebo patients. Median duration after initial occurrence of nausea for both groups was 5 days. Overall, rates of discontinuation due to AEs were 5.1\% for vilazodone patients and $1.7 \%$ for placebo patients. Most AEs were of mild-to-moderate intensity; $6.4 \%$ of vilazodone patients and $5.6 \%$ of placebo patients had a severe" AE. As measured by the Columbia Suicide Severity Rating Scale, there were no incidences of suicidal ideation or behavior that were reported as TEAEs during the study in either group. Treatment-related effects on sexual function as measured by the Changes in Sexual Functioning Questionnaire (CSFQ) $)^{62,63}$ were small and similar to placebo. Effects on weight were no different from placebo.

In a 2014 study, Mathews et $\mathrm{al}^{14}$ described an 8-week course of $20 \mathrm{mg}(\mathrm{n}=288)$ and $40 \mathrm{mg}$ vilazodone $(\mathrm{n}=287)$ 
versus citalopram $40 \mathrm{mg}(\mathrm{n}=282)$ versus placebo $(\mathrm{n}=281)$. They found that rates of TEAEs were similar for vilazodone $20 \mathrm{mg}$ (72.2\%), vilazodone $40 \mathrm{mg}$ (77.4\%), and citalopram (77.0\%) and placebo (63.3\%). TEAEs, including diarrhea, nausea, vomiting, and insomnia, occurred in $\geq 5 \%$ of the vilazodone group and $0.7 \%$ in the placebo group. The majority of TEAEs were of mild or moderate severity. Serious AEs were reported in four vilazodone $20 \mathrm{mg}$ patients, four vilazodone $40 \mathrm{mg}$ patients, and six citalopram patients. Reportedly, both vilazodone groups had greater improvement on the CSFQ relative to citalopram; differences were not statistically significant.

Croft et al $^{13}$ compared vilazodone $40 \mathrm{mg}$ /day versus placebo. AEs were similar to those reported in the other RCTs, with the most common AEs being diarrhea, nausea, dizziness, and insomnia. Interestingly, the gastrointestinal side effects, including nausea and diarrhea, were demonstrated to occur very early in treatment with vilazodone, almost always within the 1 st week. Diarrhea was seen in $32.5 \%$ and nausea in $24.7 \%$ of vilazodone-treated patients, compared to $10.3 \%$ and $8.3 \%$, respectively, of placebo-treated patients; $77.3 \%$ of vilazodone treated patients reported one or more TEAEs versus $61.7 \%$ of placebo treated patients. Discontinuation due to AEs was seen in $6.3 \%$ with active treatment versus $5.1 \%$ with placebo.

Patkar et $\mathrm{al}^{46}$ (in a dose-switching study) found there were no significant differences between the three vilazodone starting-dose groups $(10,20$, and $40 \mathrm{mg} /$ day $)$ in DESS scores when switching from SSRI to SNRI medications. Overall, vilazodone appeared to be relatively well tolerated for patients switching medications, with improvement in MADRS scores and Arizona Sexual Experiences Scale $(\mathrm{ASEX})^{64}$ scores showed decrease from baseline (17.5 \pm 5.2$)$ to end point $(15.9 \pm 6.3, P=0.01)$. Dry mouth $(\mathrm{n}=55)$, nausea $(n=10)$, and diarrhea $(n=5)$ were the most common side effects, with diarrhea reported in 5 subjects in the $40 \mathrm{mg}$ /day initiation group. Significant discontinuation-emergent scores were not observed 1 week after discontinuing vilazodone.

\section{Long-term safety and tolerability}

Robinson et $\mathrm{al}^{47}$ (ClinicalTrials.gov NCT00644358) evaluated the long-term safety of vilazodone, and concluded that $40 \mathrm{mg} /$ day for 1 year was safe and well tolerated by adults with MDD. An open-label, multicenter study, it enrolled patients with a 17 -item HAMD score of $\geq 18$. Patients took vilazodone on a fixed-titration schedule to reach a dose of $40 \mathrm{mg}$ /day, which was continued for up to 1 year. There were 599 patients, of which 254 completed 1 full year of treatment.
MADRS mean scores were $29.9 \pm 4.5$ at baseline, $11.4 \pm 7.6$ at week 8, and 7.1 \pm 7.4 at week 52 (observed cases). The CGI-S and CGI-I scores followed a similar trend. Mean CGI-S improved from $4.3 \pm 0.5$ at baseline to $2.5 \pm 1$.1 at week 8 and $1.7 \pm 1.1$ at 1 year. Similarly, the CGI-I mean score improved from $3.5 \pm 0.7$ at week 1 to $1.9 \pm 0.9$ at week 8 and $1.4 \pm 0.8$ at 1 year. CSFQ mean scores (observed cases) improved throughout treatment for both males and females. The most frequent AEs were diarrhea (35.7\%), nausea (31.6\%), and headache $(20.0 \%)$. More than $90 \%$ of these AEs were considered mild or moderate. AEs that led to discontinuation in more than $1 \%$ of patients were nausea $(1.3 \%)$ and diarrhea (1.2\%). Robinson et $\mathrm{al}^{47}$ reported a mean weight increased of $1.7 \mathrm{~kg}$ (observed cases), and reported no clinically important changes in physical examinations, electrocardiograms, or clinical chemistries. They concluded that vilazodone $40 \mathrm{mg} /$ day for 1 year was safe and well tolerated by adults.

\section{Elderly}

To our knowledge, there are no reported data on the use of vilazodone in the elderly. ClinicalTrials.gov lists one 12-week study, which is listed as currently recruiting: Vilazodone for Treatment of Geriatric Depression, in which vilazodone will be studied in 80 patients $\geq 60$ years of age with one-to-one assignment to vilazodone up to $40 \mathrm{mg}$ /day or paroxetine up to $30 \mathrm{mg} /$ day.

\section{Children/adolescents}

To our knowledge, there are no reported data on the use of vilazodone in children or adolescents either. ClinicalTrials.gov lists one 8-week study, which is listed as currently recruiting: Safety and Efficacy of Vilazodone in Adolescent Patients with Major Depressive Disorder, in which vilazodone (15 or $30 \mathrm{mg} /$ day) will compared to placebo in an 8-week study in 495 adolescents aged 12-17 years to assess both safety and efficacy.

\section{Patients with comorbid medical conditions}

Vilazodone has been studied for patients with mild-tomoderate renal impairment, a Phase I study in which subjects received $20 \mathrm{mg}$ /day of vilazodone for 14 days. Boinpally et $\mathrm{a}^{65}$ concluded that "systemic exposure of vilazodone is not affected by mild or moderate renal impairment", and no dosage adjustments were recommended for such patients. The package insert for Viibryd ${ }^{66}$ does not list any additional information about the use of vilazodone in patients with comorbid medical conditions, other than stating "Vilazodone is eliminated primarily by hepatic metabolism. In mild, 
moderate, and severe hepatic impairment, no dose adjustment is necessary".

\section{Patients with substance-abuse disorders}

We were unable to find reports of vilazodone use in patients with comorbid substance-abuse disorders. In Phase III studies reported by Robinson et $\mathrm{al}^{47}$ and Khan et al, ${ }^{12}$ active alcohol and other substance abuse were exclusions for study participation.

As noted earlier, there is an ongoing study of vilazodone for treatment of marijuana abuse, listed on ClinicalTrials.gov. This study aims to enroll 76 subjects aged 18-65 years with active marijuana dependence who will be treated with vilazodone $40 \mathrm{mg} /$ day versus placebo, with a primary outcome of negative urine toxicology for marijuana at 8 weeks. All subjects will also receive contingency-management therapy and motivational enhancement therapy.

\section{Medication interactions}

Vilazodone is extensively metabolized in the liver, primarily via the CYP3A4 isoenzyme. CYP2C19 and CYP2D6 are minor metabolic pathways. ${ }^{29}$ Only $1 \%-2 \%$ of the drug is excreted unchanged in the urine or feces. It is also metabolized by other pathways, possibly by carboxylesterase. It has also been found to be a significant CYP2C8 inhibitor. As such, concomitant use of vilazodone with other medications may affect plasma concentrations. For instance, coadministration of vilazodone with ketoconazole could increase vilazodone concentrations by approximately $50 \% .{ }^{67}$ Coadministration of vilazodone with monoamine oxidase-inhibitor medications is contraindicated, similarly to other SSRIs (see Spina et al for a further description of possible medication interactions). ${ }^{67}$ The package insert for Viibryd ${ }^{66}$ recommends that vilazodone dosing be decreased by $50 \%$ when used in combination with strong CYP3A4 inhibitors (such as erythromycin), and that dosing be increased up to twofold when used concomitantly with strong CYP3A4 inducers, such as carbamazepine, up to a maximum of $80 \mathrm{mg} /$ day. ${ }^{68}$ Also similarly to other SSRIs, vilazodone could potentiate risk of bleeding among patients concomitantly using aspirin or nonsteroidal antiinflammatory drugs.

\section{Safety in pregnancy/postpartum}

There are no adequate well-controlled studies of vilazodone in pregnant women. ${ }^{28}$ The effect of vilazodone on labor and delivery in humans is unknown. Vilazodone is excreted into the milk of lactating rats (Forest Pharmaceuticals). The effect of vilazodone on lactation and nursing in humans is unknown. In the Physicians' Desk Reference, vilazodone (Viibryd) is listed within Category C, with the notation "caution in nursing". (The FDA characterizes Schedule C drugs as drugs for which "Animal reproduction studies have shown an adverse effect on the fetus and there are no adequate and well-controlled studies in humans, but potential benefits may warrant use of the drug in pregnant women despite potential risks".)

There is one published case report of the use of vilazodone in pregnancy ${ }^{69}$ that reported that a 32-year-old woman who unexpectedly became pregnant while on $40 \mathrm{mg} /$ day vilazodone, continued medication, and gave birth to a healthy child. Other than transient neonatal jaundice, the child did not experience irritability or feeding or respiratory difficulties, which have been reported in neonates exposed to antidepressants during pregnancy.

\section{Sexual dysfunction}

In these studies, sexual dysfunction has been defined as a total ASEX score $\geq 19$, a score $\geq 5$ on any item, or a score $\geq 4$ on at least three items, ${ }^{11}$ or on the CFSQ as a total score of $\geq 47$ in men and $\geq 41$ in women for global sexual dysfunction. ${ }^{12,47}$

In the Rickels et al ${ }^{11} 8$-week study in which 205 patients were treated with vilazodone titrated up to $40 \mathrm{mg} /$ day and 205 treated with placebo, ASEX scores did not point to treatmentassociated sexual side effects for vilazodone patients. ${ }^{64} \mathrm{At}$ baseline, mean ASEX scores among men were 16.5 for vilazodone patients and 15.8 for placebo patients, and among women, the mean ASEX score was 21.2 in both groups. Differences of the observed ASEX mean scores between baseline and week 8 suggested overall slight improvement in sexual function, and apparently did not differ between vilazodone and placebo.

Khan et $\mathrm{al}^{12}$ found that mean CSFQ scores at baseline in the vilazodone and placebo groups were 46.5 and 46.6 for men and 39.4 and 40.2 for women, respectively. At week 8 , for men, mean CFSQ total score change from baseline in vilazodone patients showed improvement of $0.6 \pm 7.9$, and in placebo showed improvement of $1.8 \pm 6.4$ points. The most common sexual dysfunction AE was decreased libido, which was reported by $4.7 \%$ of vilazodone patients, and no placebo patients. Overall, there were 21 sexual dysfunction AEs in the vilazodone group, and one in the placebo group. Khan et $\mathrm{al}^{12}$ noted, "There were differences between qualitative (adverse events) and quantitative (CSFQ) measures of the effect of vilazodone on sexual function. This inconsistency may reflect the difficulty in distinguishing sexual dysfunction related to antidepressants from sexual dysfunction related to 
depression itself. Further exploration of the subscales of the CSFQ and the reported adverse events might help to clarify these differences".

Phelps ${ }^{70}$ however, has criticized these studies, stating that they are flawed by 1) enrolling patients with preexisting sexual dysfunction, rather than only patients without preexisting sexual dysfunction, and 2) the absence of an SSRI comparator. Indeed, as Phelps states, "The FDA agrees with our skepticism. In an email to The Carlat Psychiatry Report, Dr Thomas Laughren, who is the director of psychiatric products at the FDA, described for us the standards the FDA requires for antidepressant makers to claim their products do not cause sexual dysfunction, and he assured us that 'vilazodone has not met that standard'. Clinical Data has been officially barred by the FDA from touting vilazodone as a low sexual side-effect antidepressant". ${ }^{70}$

Subsequently, Clayton et $\mathrm{a}^{49}$ further reported on data from two double-blind vilazodone-versus-placebo studies $(n=869$; vilazodone $n=436$, placebo-treated $n=433)$ and one open-label vilazodone study $(\mathrm{n}=599)$. Over half of the patients had sexual dysfunction at baseline $(50 \%$ of men, $68 \%$ of women). ${ }^{13}$ As Clayton et $\mathrm{al}^{49}$ concluded, “. . s sexual function improved on average in both vilazodone and placebo groups. Results suggest that vilazodone may have a small adverse impact on sexual function in adults with MDD relative to the high prevalence of sexual dysfunction at baseline". Subsequently, one study has addressed the concern of a lack of active comparator medication. ${ }^{48}$

Mathews et a ${ }^{14}$ reported that both vilazodone-treated groups ( $20 \mathrm{mg} /$ day and $40 \mathrm{mg} /$ day) had greater improvement on the CSFQ relative to citalopram $40 \mathrm{mg}$ /day and placebo, but that these differences were not statistically significant. In a post hoc analysis of this cohort (NCT01473394) reported in a recent Association of Collegiate Schools of Planning abstract, Mathews et al ${ }^{48}$ found that the rates of sexual dysfunction were similar for vilazodone ( $20 \mathrm{mg}, \mathrm{n}=267 ; 40 \mathrm{mg}$, $n=259)$-, citalopram $(n=257)-$, and placebo $(n=264)$-treated patients who had baseline and one postbaseline CSFQ rating. About half of the patients had sexual dysfunction at baseline (defined as CSFQ score $\leq 47$ for men and $\leq 41$ for women, with lower scores indicating worse dysfunction). ${ }^{55}$ In patients with normal baseline sexual function, $12 \%$ of placebo patients, $16 \%$ of vilazodone $20 \mathrm{mg}$ /day patients, $15 \%$ of vilazodone $40 \mathrm{mg}$ /day patients, and $17 \%$ of citalopram patients met criteria for sexual dysfunction at two consecutive double-blind visits. Overall, following treatment, mean CSFQ scores increased in all groups, suggesting improvement in sexual functioning. In patients with baseline sexual dysfunction, $33 \%$ of placebo, $35 \%$ of vilazodone $20 \mathrm{mg} /$ day, $30 \%$ of vilazodone $40 \mathrm{mg} / \mathrm{day}$, and $28 \%$ of citalopram $40 \mathrm{mg}$ /day patients improved to normal sexual function after 10 weeks.

In Patkar et al's ${ }^{46}$ abstract of a medication-switching study, ASEX scores showed a decrease from baseline (17.5 \pm 5.2$)$ to end point (15.9 $\pm 6.3, P=0.01)$ among patients switched from SSRI and SNRI medications to vilazodone, but this abstract did not report detailed statistics.

The third hypothesized advantage ${ }^{9}$ of vilazodone as an SPARI was lower sexual side effects. These studies do suggest that vilazodone has a relatively small adverse impact on sexual functioning. Only one comparative agent (citalopram) has been studied, and a full repor ${ }^{48}$ analyzing sexual side effects in that trial has not yet been published, so it is difficult to know whether vilazodone's sexual side-effect profile is lower than seen with SSRIs. Existing data have other limitations: for instance, none of the cited studies enrolled only patients without preexisting sexual dysfunction. It is also possible that other methodological factors have limited the accuracy of study findings (for example, the ASEX, a five-question inventory that asks about sexual drive, arousal, penile erection/vaginal lubrication, orgasm, and satisfaction from orgasm) may not be a very sensitive instrument for assessing sexual dysfunction among participants in pharmacological trials.

Two ongoing studies listed on ClinicalTrials.gov relate to sexual dysfunction and may help to clarify these issues: 1) Does Vilazodone Help with Antidepressant-Associated Sexual Dysfunction? (which will enroll patients treated with SSRIs with antidepressant-associated sexual dysfunction, who will be switched to vilazodone or sertraline for 11 weeks, and rated on the (SFQ); and 2) a study to evaluate the functioning of healthy adults after receiving vilazodone 20 or $40 \mathrm{mg}$, paroxetine $20 \mathrm{mg}$, or placebo (which will study effects of these treatments on healthy adults without preexisting sexual dysfunction, who will be treated for 35 days, rated on the CSFQ, and the percentage with sexual dysfunction).

\section{Place in therapy}

At this point, vilazodone cannot be recommended as a firstline drug for treatment of depression, primarily for cost reasons. It has a generally similar mechanism of action to existing drugs. Despite theoretical advantages of SPARI drugs, such as more rapid onset of action, more complete response, or fewer side effects, as postulated by Stahl, ${ }^{9}$ these actions have not been strongly supported to date in published studies. Furthermore, data for superiority in subpopulations 
(such as depression with high anxiety or anxious distress) or fewer side effects (such as sexual dysfunction) is not convincing. Therefore, there does not yet appear to be a compelling case for use of vilazodone as a first-line antidepressant drug. In particular, all of the SSRIs and most of the SNRIs are currently available in generic forms, and are substantially less expensive than vilazodone: the monthly cost for Viibryd in New York City is $\$ 177$ for thirty 20-mg tablets, compared to $\$ 14$ for thirty $20-\mathrm{mg}$ escitalopram.

As noted earlier, vilazodone could potentially be useful for various subgroups of patients, such as those with depression and comorbid anxiety, and possibly patients with sexual side effects on SSRIs or other antidepressants. Also, it is possible that some nonresponders to SSRIs and SNRIs will respond to vilazodone: some such individuals may have abnormalities of 5- $\mathrm{HT}_{1 \mathrm{~A}}$ function that are not addressed by reuptake inhibition of serotonin or norepinephrine. The $5-\mathrm{HT}_{1 \mathrm{~A}}$ partial agonism of vilazodone may indeed have benefits for particular subgroups of patients, as suggested based on pharmacological hypotheses ${ }^{9}$ and animal data. ${ }^{8}$ However, there is a need for additional evidence from Phase IV studies to support its clinical benefit in humans.

\section{Unmet needs}

Given the worse outcome for MDD patients with comorbid anxiety symptoms ${ }^{56}$ (or in DSM-5 terms, anxious distress), it would be valuable to find effective monotherapies that could treat both the mood disorder and coexisting anxiety symptoms. In addition, vilazodone could be useful for patients with primary anxiety-disorder diagnoses, such as generalized anxiety disorder, social phobia, and panic disorder. For each of these disorders, it would be essential to determine whether vilazodone is effective compared to placebo, and then whether it has additional benefit, in terms of efficacy or tolerability, in comparison to SSRIs. It would also be interesting to know whether patients with obsessivecompulsive disorder respond to vilazodone in comparison to placebo and SSRIs. The same would apply to those patients who have MDD along with comorbid anxiety disorders. Similarly, in posttraumatic stress disorder, which the DSM-5 has categorized among the trauma- and stress-related disorders, it would be valuable to determine whether vilazodone is efficacious, both in comparison to placebo and SSRIs; in particular, the impact of 5-HT $\mathrm{HA}_{1 \mathrm{~A}}$ partial agonists on fear conditioning ${ }^{71}$ and the literature on buspirone augmentation of SSRI medication. ${ }^{72}$

Other unmet needs for antidepressants in general include faster-onset medications and antidepressant medications with improved tolerability, with lower rates of weight gain, sexual dysfunction, and other common side effects, and medications with better tolerability for patients with comorbid medical conditions.

The relative economic outcomes for vilazodone treatment versus other agents should be determined. Particularly if vilazodone was to show more efficacy for anxiety symptoms among depressed individuals, or comorbid anxiety disorders, it would be valuable to determine whether this leads to better outcomes in economic terms, including work absences, work productivity, and unemployment/underemployment, as well as health services utilization.

\section{Disclosure}

DH has conducted studies that have been funded by companies including Pfizer (current), and past studies that were funded by companies including Eli Lilly, Wyeth, BristolMyers Squibb, and Forest Pharmaceuticals. JF reports no conflicts of interest in this work.

\section{References}

1. Murray CJ, Vos T, Lozano R, et al. Disability-adjusted life years (DALYs) for 291 diseases and injuries in 21 regions, 1990-2010: a systematic analysis for the Global Burden of Disease Study 2010. Lancet. 2013;380(9859):2197-2223.

2. World Health Organization. Global burden of mental disorders and the need for a comprehensive, coordinated response from health and social sectors at the country level. 2012. Available from: http://www. ghwatch.org/who-watch/wha65/mental. Accessed January 29, 2015.

3. Kessler RC, Birnbaum H, Demler O, et al. The prevalence and correlates of nonaffective psychosis in the National Comorbidity Survey Replication (NCS-R). Biol Psychiatry. 2005;58(8):668-676.

4. Greenberg PE, Kessler RC, Birnbaum HG, et al. The economic burden of depression in the United States: how did it change between 1990 and 2000? J Clin Psychiatry. 2003;64(12):1465-1475.

5. Stewart JW, McGrath PJ, Blondeau C, et al. Combination antidepressant therapy for major depressive disorder: speed and probability of remission. J Psychiatr Res. 2014;52:7-14.

6. Geddes JR, Carney SM, Davies C, et al. Relapse prevention with antidepressant drug treatment in depressive disorders: a systematic review. Lancet. 2003;361(9358):653-661.

7. Trivedi M, Lin E, Katon W. Consensus recommendations for improving adherence, self-management, and outcomes in patients with depression. CNS Spectr. 2007;12(8 Suppl 13):1-27.

8. Hughes ZA, Starr KR, Langmead CJ, et al. Neurochemical evaluation of the novel 5-HT1A receptor partial agonist/serotonin reuptake inhibitor, vilazodone. Eur J Pharmacol. 2005;510(1):49-57.

9. Stahl SM. Mechanism of action of the SPARI vilazodone: serotonin 1A partial agonist and reuptake inhibitor. CNS Spectr. 2014;19(2): $105-109$.

10. Trivedi MH, Rush AJ, Wisniewski SR, et al. Evaluation of outcomes with citalopram for depression using measurement-based care in STAR*D: implications for clinical practice. Am J Psychiatry. 2006; 163(1):28-40.

11. Rickels K, Athanasiou M, Robinson DS, Gibertini M, Whalen H, Reed CR. Evidence for efficacy and tolerability of vilazodone in the treatment of major depressive disorder: a randomized, double-blind, placebo-controlled trial. J Clin Psychiatry. 2009;70(3):326-333. 
12. Khan A, Cutler AJ, Kajdasz DK, et al. A randomized, double-blind, placebo-controlled, 8-week study of vilazodone, a serotonergic agent for the treatment of major depressive disorder. J Clin Psychiatry. 2011;72(4):441-447.

13. Croft HA, Pomara N, Gommoll C, Chen D, Nunez R, Mathews M. Efficacy and safety of vilazodone in major depressive disorder: a randomized, double-blind, placebo-controlled trial. J Clin Psychiatry. 2014;75(11):e1291-e1298.

14. Mathews M, Gommoll C, Chen D, Nunez R, Khan A. Efficacy and safety of vilazodone 20 and $40 \mathrm{mg}$ in major depressive disorder: a randomized, double-blind, placebo-controlled trial. Int Clin Psychopharmacol. Epub December 12, 2014.

15. Reed CR, Kajdasz DK, Whalen H, Athanasiou MC, Gallipoli S, Thase ME. The efficacy profile of vilazodone, a novel antidepressan for the treatment of major depressive disorder. Curr Med Res Opin. 2011;28(1):27-39.

16. Blier P, Ward NM. Is there a role for 5-HT1A agonists in the treatment of depression? Biol Psychiatry. 2003;53(3):193-203.

17. Rickels K, Athanasiou M, Reed C. Vilazodone, a novel, dual-acting antidepressant: current status, future promise and potential for individualized treatment of depression. Per Med. 2009;6(2):217-224.

18. Fava M, Rush AJ, Alpert JE, et al. Difference in treatment outcome in outpatients with anxious versus nonanxious depression: a STAR*D report. Am J Psychiatry. 2008;165(3):342-351.

19. Thase ME, Chen D, Edwards J, Ruth A. Efficacy of vilazodone on anxiety symptoms in patients with major depressive disorder. Int Clin Psychopharmacol. 2014;29(6):351-356.

20. Friedman RA. A dry pipeline for psychiatric drugs. $N$ Y Times. Epub August 19, 2013.

21. Murrough JW, Charney DS. Is there anything really novel on the antidepressant horizon? Curr Psychiatry Rep. 2012;14(6):643-649.

22. Krystal JH, Sanacora G, Duman RS. Rapid-acting glutamatergic antidepressants: the path to ketamine and beyond. Biol Psychiatry. 2013;73(12):1133-1141

23. Asnis GM, Bose A, Gommoll CP, Chen C, Greenberg WM. Efficacy and safety of levomilnacipran sustained release $40 \mathrm{mg}, 80 \mathrm{mg}$, or $120 \mathrm{mg}$ in major depressive disorder: a phase 3, randomized, doubleblind, placebo-controlled study. J Clin Psychiatry. 2013;74(3): 242-248

24. Katona CL, Katona CP. New generation multi-modal antidepressants: focus on vortioxetine for major depressive disorder. Neuropsychiatr Dis Treat. 2014;10:349-354.

25. Mørk A, Montezinho LP, Miller S, et al. Vortioxetine (Lu AA21004), a novel multimodal antidepressant, enhances memory in rats. Pharmacol Biochem Behav. 2013;105:41-50.

26. Theunissen EL, Street D, Højer AM, Vermeeren A, van Oers A, Ramaekers JG. A randomized trial on the acute and steady-state effects of a new antidepressant, vortioxetine (Lu AA21004), on actual driving and cognition. Clin Pharmacol Ther. 2013;93(6):493-501.

27. Choi E, Zmarlicka M, Ehret MJ. Vilazodone: a novel antidepressant Am J Health Syst Pharm. 2012;69(18):1551-1557.

28. Citrome L. Vilazodone for major depressive disorder: a systematic review of the efficacy and safety profile for this newly approved antidepressant - what is the number needed to treat, number needed to harm and likelihood to be helped or harmed? Int J Clin Pract. 2012;66(4): 356-368.

29. Cruz MP. Vilazodone $\mathrm{HCl}$ (Viibryd): a serotonin partial agonist and reuptake inhibitor for the treatment of major depressive disorder. $P T$. 2012;37(1):28-31.

30. Culpepper L, Mathews M, Ghori R, Edwards J. Clinical relevance of vilazodone treatment in patients with major depressive disorder: categorical improvement in symptoms. Prim Care Companion CNS Disord. 2014;16(1).

31. Dawson LA, Watson JM. Vilazodone: a 5-HT1A receptor agonist/ serotonin transporter inhibitor for the treatment of affective disorders CNS Neurosci Ther. 2009;15(2):107-117.

32. Frampton JE. Vilazodone. CNS Drugs. 2011;25(7):615-627.
33. Griffin J, Pappas M. Drug Class Review. Second-Generation Antidepressants. Single Drug Addendum: Vilazodone $\mathrm{HCl}$. Portland: Oregon Health and Science University; 2013.

34. Laughren TP, Gobburu J, Temple RJ, et al. Vilazodone: clinical basis for the US Food and Drug Administration's approval of a new antidepressant. J Clin Psychiatry. 2011;72(9):1166-1173.

35. Hansen RA, Gartlehner G, Lohr KN, Gaynes BN, Carey TS. Efficacy and safety of second-generation antidepressants in the treatment of major depressive disorder. Ann Intern Med. 2005;143(6):415-426.

36. Kirsch I, Deacon BJ, Huedo-Medina TB, Scoboria A, Moore TJ, Johnson BT. Initial severity and antidepressant benefits: a meta-analysis of data submitted to the Food and Drug Administration. PLoS Med. 2008;5(2):e45.

37. Fournier JC, DeRubeis RJ, Hollon SD, et al. Antidepressant drug effects and depression severity: a patient-level meta-analysis. JAMA. 2010;303(1):47-53.

38. Rush AJ, Trivedi MH, Wisniewski SR, et al. Acute and longer-term outcomes in depressed outpatients requiring one or several treatment steps: a STAR*D report. Am J Psychiatry. 2006;163(11):1905-1917.

39. Machado-Vieira R, Salvadore G, Diazgranados N, Zarate Jr CA Ketamine and the next generation of antidepressants with a rapid onset of action. Pharmacol Ther. 2009;123(2):143-150.

40. Sachs GS, Nierenberg AA, Calabrese JR, et al. Effectiveness of adjunctive antidepressant treatment for bipolar depression. $N$ Engl J Med. 2007;356(17):1711-1722.

41. American Psychiatric Association. Diagnostic and Statistical Manual of Mental Disorders. 5th ed. Arlington (VA): APA; 2013.

42. Bartoszyk GD, Hegenbart R, Ziegler H. EMD 68843, a serotonin reuptake inhibitor with selective presynaptic 5-HT1A receptor agonistic properties. Eur J Pharmacol. 1997;322(2):147-153.

43. Schwarz TL, Siddiqui UA, Stahl SM. Vilazodone: a brief pharmacologic and clinical review of the novel serotonin partial agonist and reuptake inhibitor. Ther Adv Psychopharmacol. 2011;1(3):81-87.

44. Page ME, Cryan JF, Sullivan A, et al. Behavioral and neurochemical effects of 5-\{4-[4-(5-Cyano-3- indolyl)-butyl)-butyl]-1-piperazinyl $\}$ benzofuran-2-carboxamide (EMD 68843): a combined selective inhibitor of serotonin reuptake and 5-hydroxytryptamine1A receptor partial agonist. J Pharmacol Exp Ther. 2002;302(3):1220-1227.

45. Rabiner EA, Gunn RN, Wilkins MR, et al. Drug action at the 5-HT(1A) receptor in vivo: autoreceptor and postsynaptic receptor occupancy examined with PET and [carbonyl-(11)C]WAY-100635. Nucl Med Biol. 2000;27(5):509-513.

46. Patkar A, Rele S, Millet M, et al. A 8-week randomized, double-blind trial comparing efficacy, safety and tolerability of three vilazodone dose initiation strategies following switch from SSRIs or SNRIs in major depressive disorder. 2014. Available from: https://guidebook. com/guide/23750/poi/2064209. Accessed January 29, 2015.

47. Robinson DS, Kajdasz DK, Gallipoli S, Whalen H, Wamil A, Reed CR. A 1-year, open-label study assessing the safety and tolerability of vilazodone in patients with major depressive disorder. J Clin Psychopharmacol. 2011;31(5):643-646.

48. Mathews MG, Chen C, Dalei NR. Effects of vilazodone on sexual dysfunction in major depressive disorder: a randomized, double-blind trial with placebo and active controls. Poster presented at: ASCP 2014; October 8-10, 2014: Tampa, FL.

49. Clayton AH, Kennedy SH, Edwards JB, Gallipoli S, Reed CR. The effect of vilazodone on sexual function during the treatment of major depressive disorder. J Sex Med. 2013;10(10):2465-2476.

50. Citrome L, Gommoll CP, Tang X, Nunez R, Mathews M. Evaluating the efficacy of vilazodone in achieving remission in patients with major depressive disorder: post-hoc analyses of a phase IV trial. Int Clin Psychopharmacol. 2015;30(2):75-81.

51. Rosenbaum JF, Fava M, Hoog SL, Ascroft RC, Krebs WB. Selective serotonin reuptake inhibitor discontinuation syndrome: a randomized clinical trial. Biol Psychiatry. 1998;44(2):77-87.

52. Pierz KA, Thase ME. A review of vilazodone, serotonin, and major depressive disorder. Prim Care Companion CNS Disord. 2014;16(1). 
53. Szegedi A, Jansen WT, Van Willigenburg A, van der Meulen E, Stassen $\mathrm{HH}$, Thase ME. Early improvement in the first 2 weeks as a predictor of treatment outcome in patients with major depressive disorder: a meta-analysis including 6562 patients. J Clin Psychiatry. 2009;70(3):344-353.

54. Citrome L, Gommoll CP, Tang X, Nunez R, Mathews M. The efficacy of vilazodone in achieving remission in patients with major depressive disorder: post-hoc analyses of a Phase IV trial. Int Clin Psychopharmacol. 2015;30(2):75-81.

55. Bielski RJ, Cunningham L, Horrigan JP, Londborg PD, Smith WT, Weiss K. Gepirone extended-release in the treatment of adult outpatients with major depressive disorder: a double-blind, randomized, placebo-controlled, parallel-group study. J Clin Psychiatry. 2008;69(4): 571-577.

56. Fava M, Rush A, Alpert J, et al. Difference in treatment outcome in outpatients with anxious versus nonanxious depression: a STAR* D report. Am J Psychiatry. 2008;165(3):342-351.

57. Alpert JE, Franznick DA, Hollander SB, Fava M. Gepirone extendedrelease treatment of anxious depression: evidence from a retrospective subgroup analysis in patients with major depressive disorder. $J$ Clin Psychiatry. 2004;65(8):1069-1075.

58. Gammans R, Stringfellow J, Hvizdos AJ, et al. Use of buspirone in patients with generalized anxiety disorder and coexisting depressive symptoms. Neuropsychobiology. 1992;25(4):193-201.

59. Hamilton M. The assessment of anxiety states by rating. $\mathrm{Br} \mathrm{J} \mathrm{Med}$ Psychol. 1959;32(1):50-55.

60. Hamilton M. A rating scale for depression. J Neurol Neurosurg Psychiatry. 1960;23:56-62.

61. Nelson JC. Anxiety does not predict response to duloxetine in major depression: results of a pooled analysis of individual patient data from 11 placebo-controlled trials. Depress Anxiety. 2010;27(1):12-18.
62. Clayton AH, McGarvey EL, Clavet GJ. The Changes in Sexual Functioning Questionnaire (CSFQ): development, reliability, and validity. Psychopharmacol Bull. 1997;33(4):731-745.

63. Keller A, McGarvey EL, Clayton AH. Reliability and construct validity of the Changes in Sexual Functioning Questionnaire short-form (CSFQ-14). J Sex Marital Ther. 2006;32(1):43-52.

64. McGahuey CA, Gelenberg AJ, Laukes CA, et al. The Arizona sexual experience scale (ASEX): reliability and validity. J Sex Marital Ther. 2000;26(1):25-40.

65. Boinpally R, Alcorn H, Adams MH, Longstreth J, Edwards J. Pharmacokinetics of vilazodone in patients with mild or moderate renal impairment. Clin Drug Investig. 2013;33(3):199-206.

66. Viibryd [package insert]. St Louis: Forest Pharmaceuticals; 2014.

67. Spina E, Trifirò G, Caraci F. Clinically significant drug interactions with newer antidepressants. CNS Drugs. 2012;26(1):39-67.

68. Boinpally R, Gad N, Gupta S, Periclou A. Influence of CYP3A4 induction/inhibition on the pharmacokinetics of vilazodone in healthy subjects. Clin Ther. 2014;36(11):1638-1649.

69. Morrison CM. A case report of the use of vilazodone in pregnancy. Prim Care Companion CNS Disord. 2013;16(2).

70. Phelps J. Four "new" antidepressants. Or are they? 2011. Available from: http://www.thecarlatreport.com/free_articles/four- $\% \mathrm{E} 2 \%$ $80 \% 9 \mathrm{Cnew} \% \mathrm{E} 2 \% 80 \% 9 \mathrm{D}$-antidepressants-or-are-they-free-article. Accessed January 29, 2015.

71. Stanhope K, Dourish C. Effects of 5-HT1A receptor agonists, partial agonists and a silent antagonist on the performance of the conditioned emotional response test in the rat. Psychopharmacology. 1996;128(3):293-303.

72. Hamner M, Ulmer H, Horne D. Buspirone potentiation of antidepressants in the treatment of PTSD. Depress Anxiety. 1997;5(3): $137-139$
Core Evidence

\section{Publish your work in this journal}

Core Evidence is an international, peer-reviewed open-access journal evaluating the evidence underlying the potential place in therapy of drugs throughout their development lifecycle from preclinical to postlaunch. The focus of each review is to evaluate the case for a new drug or class in outcome terms in specific indications and patient groups.

\section{Dovepress}

The manuscript management system is completely online and includes a very quick and fair peer-review system, which is all easy to use. Visit http://www.dovepress.com/testimonials.php to read real quotes from published authors. 